\title{
SYNTHESIS OF SOME NEW BIOACTIVE 1-N-SUBTITUTED 3, 5-DIARYL-2- PYRAZOLINES
}

\author{
Sadaf Sadiq Khan and Aurangzeb Hasan" \\ Department of Chemistry, Quaid-i-Azam University, Islamabad 45320, Pakistan \\ E-mail: flavonoids@hotmail.com
}

\begin{abstract}
A group of four series (A-D) of 22 new bioactive 1-N-acid substituted 3, 5-diphenyl-2-pyrazolines were synthesized by cyclization of variably substituted chalcones and simple or substituted phenyl hydrazine and / or semicarbazide, using acetic acid as a solvent. The chemical structure of the compounds was characterized by FTIR, 'HNMR, and EIMS spectroscopy and chemical analyses. The antifungal and antibacterial activities of these compounds were evaluated by agar tube dilution method and agar well diffusion method respectively.
\end{abstract}

\section{Introduction}

In continuation of our previous work ${ }^{[1]}$ on the synthesis of pyrazolines which have displayed various biological properties such as pesticidal, fungicidal, insecticidal, anti-inflammatory, antiarthritic, antidepressant and antiviral activities ${ }^{[2-4]}$. Considerable interest has been focused on the pyrazolines structure, which is known to possess a broad spectrum of biological activities such as transquillising, muscle relaxant, psychoanaleptic, anticonvulsant and antihypertensive activities ${ }^{[5-9]}$. Moreover, these heterocyclic compounds, in addition to biological activities have also shown some industrial applications like bleaching agent, dyes, optical brighteners and various fluorescentwhitening agents ${ }^{[2,4,10-13]}$.

Earlier studies by E. Palaska, et al. ${ }^{[14]}$ also demonstrated the antidepressant activities of some 3, 5-diphenyl-2pyrazolines. The present study is therefore devoted to the synthesis of pyrazolines from variably substituted chalcones, which are also associated with diverse biological activities ${ }^{[15-20]}$, and simple or substituted phenyl hydrazine and / or semicabazide. This study was carried out in the quest to prepare pyrazolines not synthesized earlier that may possess new and/or enhanced biological and other industrial properties. As part of our continuing efforts in this area a group of four series of 22 new 1-N- substituted 3, 5-diphenyl -2- pyrazolines have been synthesized and evaluated for their antifungal and antibacterial activities

\section{Results and Discussion}

O-acetyl 4-halo-phenols (d-f) were prepared by reacting 4-halo-phenols (a-c) with acetic anhydride in the presence of pyridine. On Fries rearrangement with anhydrous $\mathrm{AlCl}_{3}(\mathrm{~d}-\mathrm{f})$ yielded 5-halo-2-hydroxy acetophenones ( $\mathrm{g}$-i). Compounds (g-i) on further reaction with various aromatic aldehydes $(j-l)$ in the presence of $50 \% \mathrm{NaOH}$ and hot ethanol were converted into 2-hydroxy substituted chalcones $\left(\mathbf{S}_{1}-\mathbf{S}_{5}\right)$, which on cyclization with phenyl hydrazine in acetic acid afforded 1-phenyl -3-(2-hydroxy -5-halo-phenyl)-5-(4-halo-phenyl)-2-pyrazolines (AS $\left.\mathbf{S}_{\mathbf{1}}-\mathbf{A S}_{\mathbf{5}}\right)$ (Scheme 1).<smiles>[X]c1ccc(O)cc1</smiles>

$(n-c)$

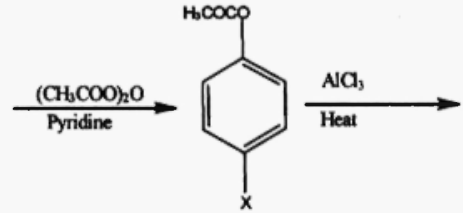

(d-1)<smiles>[X]c1ccc(O)c(C(=O)O)c1</smiles>

$(\mathbf{g}-\mathbf{i})$

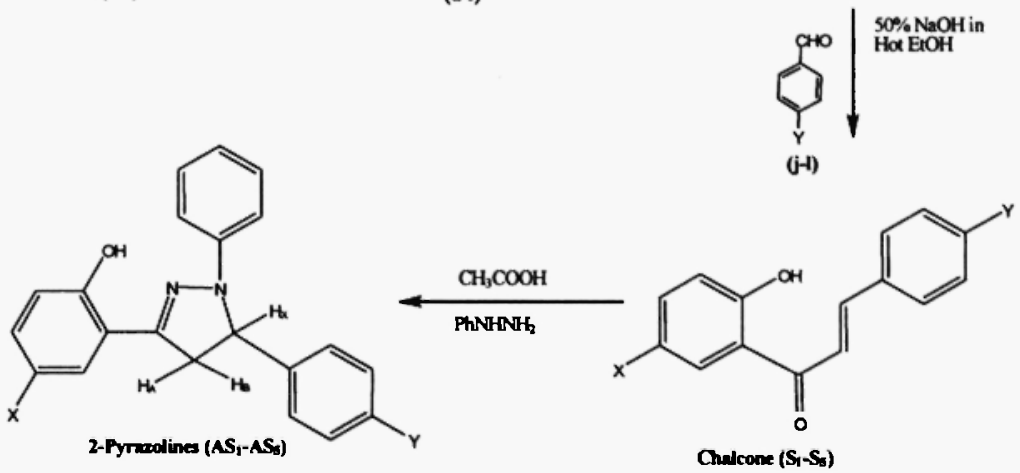


Further more, by Claisen Schmidt condensation reaction; unsubtituted acetophenone $(\mathbf{m})$ was converted to chalcones $\left(\mathbf{S}_{6}-\mathbf{S}_{13}\right)$ by reacting it with variably substituted benzaldehydes $(\mathbf{n}-\mathbf{u})$ in the presence of $10 \% \mathrm{NaOH}$ and ethanol. Chalcones $\left(\mathbf{S}_{6}-\mathbf{S}_{13}\right)$ on cyclization with phenyl hydrazine gave 2-pyrazolines $\left(\mathbf{B S}_{6}-\mathbf{B S}_{13}\right)$, chalcones $\left(\mathbf{S}_{6}, \mathbf{S}_{8}-\mathbf{S}_{10}, \mathbf{S}_{13}\right)$ with 2,4-dinitrophenylhyrdazine (2,4-DNP) gave 2-pyrazolines $\left(\mathbf{C S}_{14}-\mathbf{C S}_{18}\right)$ and chalcones $\left(\mathbf{S}_{\mathbf{6}}, \mathbf{S}_{\mathbf{8}}-\mathbf{S}_{10}\right)$ on treatment with semicabazide in the presence of acetic acid give 2-pyrazolines $\left(\mathbf{D S}_{19}-\mathbf{D S}_{22}\right)$ scheme 2.

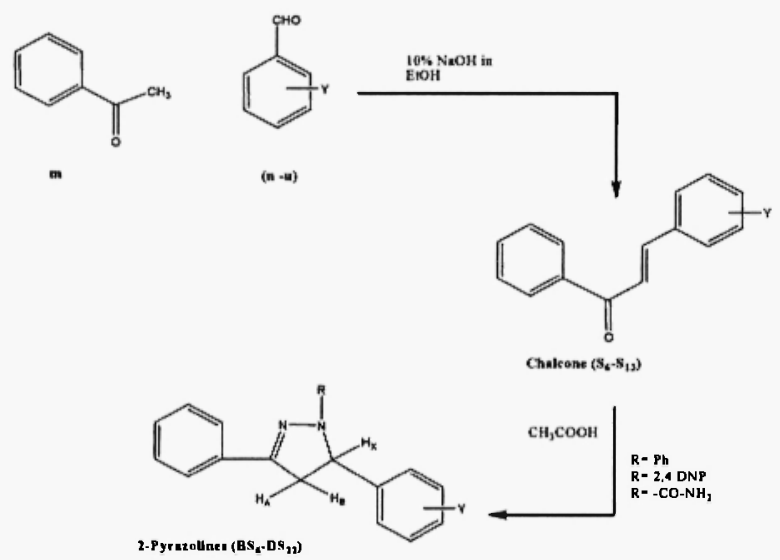

Scheme-2

1-Phenyl-3-(2-hydroxy-5-bromophenyl)-5-(4-fluorophenyl)-2-pyrazoline $\left(\mathbf{A S}_{\mathbf{1}}\right)$ was obtained as yellow grannuals. The molecular formula and molecular weight of $\left(\mathbf{A S}_{1}\right)$ are $\mathrm{C}_{21} \mathrm{H}_{16} \mathrm{~N}_{2} \mathrm{BrFO}$ and 410 respectively. The FTIR spectrum showed stretching frequencies at $3493 \mathrm{~cm}^{-1}, 3028 \mathrm{~cm}^{-1}, 1584 \mathrm{~cm}^{-1}, 1493 \mathrm{~cm}^{-1}$ which are characteristics of $\mathrm{OH}$, $\mathrm{CH}_{2}, \mathrm{C}=\mathrm{N}, \mathrm{C}=\mathrm{C}$ of the aromatic rings respectively (Table 2). The mass spectrum of 1-phenyl-3-(2-hydroxy-5bromophenyl)-5-(4-fluorophenyl)-2-pyrazoline $\left(\mathbf{A S}_{1}\right)$ showed characteristics peaks of molecular ion peak $\mathrm{M}, \mathrm{M}+2$ at $\mathrm{m} / \mathrm{z} 410,412$ respectively with relative isotopic abundance of $\mathrm{Br}$ which are found in good agreement with molecular weight. The characteristic peaks at $\mathrm{m} / \mathrm{z} 329$ and 331 appeared due to the loss of $\mathrm{Br}$ radical from molecular ion. The base peak in the mass spectrum appeared at $\mathrm{m} / \mathrm{z} 410$ which is also the molecular ion peak. Other peaks at 315 and 239 are formed from the loss of A, B and $\mathrm{C}$ ring from the molecule. The ${ }^{1} \mathrm{H}$ NMR spectrum of 1-phenyl-3-(2hydroxy-5-bromo-phenyl)-5-(4-fluorophenyl)-2-pyrazoline $\left(\mathbf{A S}_{1}\right)$ showed three doublet of doublets at $3.20 \mathrm{ppm}$, $3.92 \mathrm{ppm}, 5.25 \mathrm{ppm}$, with large coupling constant $(7.40,17.2) \mathrm{Hz},(12.36,17.2) \mathrm{Hz}$ and $(7.41,12.2) \mathrm{Hz}$ which are characteristic and showed following type of arrangement of protons.<smiles>[Y]C(C)(C)C</smiles>

The phenolic $-\mathrm{OH}$ of the ring at 3-position showed a broad singlet at $10.6 \mathrm{ppm}$. The aromatic protons are shown in the range of 6.76-7.35 ppm. The $\delta$ values, multiplicity and $\mathbf{J}$ values of all protons of 1-phenyl-3-(2-hydroxy-5bromophenyl)-5-(4-fluoro-phenyl)-2-pyrazoline $\left(\mathbf{A} \mathbf{S}_{1}\right)$ are presented in the experimental section. Similarly all other 2-prazolines $\left(\mathbf{A S}_{2}-\mathbf{D S}_{\mathbf{2}}\right)$ were characterized on the basis of their physical and spectral data.

For compounds $\mathbf{B S}_{6}-\mathbf{B S}_{13}$ there is no much difference in ${ }^{1} \mathrm{H}$ NMR and FTIR spectral data from that of $\mathrm{AS}_{1}$, except that in ${ }^{1} \mathrm{H}$ NMR spectra of B-series compounds, there is no peak due to $\mathrm{O}-\mathrm{H}$ proton and also in FTIR spectra stretching vibration due to $-\mathrm{OH}$ absorption band is absent.

The difference between $\mathbf{A} \mathbf{S}_{1}$ and $\mathrm{C}$-series $\left(\mathbf{C S}_{14}-\mathbf{C S}_{18}\right)$ compounds lies in ${ }^{\mathrm{i}} \mathrm{H}$ NMR and EIMS spectrum. In ${ }^{1} \mathrm{H}$ NMR spectrum there are downfield shift values due to 2,4-dinitrophenyl protons, which appear between 7.79-8.60 ppm. EIMS spectra of C-series compounds show fragments at [M-30] and [M-46] due to the loss of M-NO and $\mathrm{M}$ $\mathrm{NO}_{2}$ respectively.

D-series $\left(\mathbf{D S}_{19}-\mathbf{D S}_{22}\right.$ ) 2-pyrazolines differs from $\mathbf{A S}_{1}$ in their FTIR spectral data In D-series 2-pyrazolines there is a stretching band due to the carbonyl group and a sharp band due to the $\mathrm{N}-\mathrm{H}$ group of semicarbazide. Similarly in ${ }^{1} \mathrm{H}$ NMR spectral analysis, $\delta$ values between $5.70-5.87 \mathrm{ppm}$ appear which are characteristic of the $-\mathrm{NH}_{2}$ protons. In 
EIMS spectral analysis a fragment ion $[\mathrm{M}-44]^{+}$is prominent due to loss of $-\mathrm{NH}_{2}-\mathrm{C}=\mathrm{O}$ moiety.Physical data of synthesized 2-pyrazolines $\left(\mathbf{A S}_{1}-\mathbf{D S}_{22}\right)$ are listed in Table-1.

Table-1 : Structure and physical data of the compounds (AS1-DS23)

\begin{tabular}{|c|c|c|c|c|c|c|c|c|}
\hline $\begin{array}{c}\text { Compound } \\
\#\end{array}$ & $\mathbf{X}$ & $\mathbf{Y}$ & $\mathbf{R}$ & Formula & M.P ${ }^{0} \mathrm{C}$ & $\begin{array}{r}\text { Yield } \\
(\%)\end{array}$ & $\overline{\mathbf{R}_{f}}$ & Solvent* \\
\hline $\mathrm{AS}_{1}$ & $\mathrm{Br}$ & $\mathrm{F}$ & $\mathrm{Ph}$ & $\mathrm{C}_{21} \mathrm{H}_{11} \mathrm{~N}_{2} \mathrm{BrFO}$ & $180-182$ & 83 & 94 & Ethanol \\
\hline $\mathrm{AS}_{2}$ & $\mathrm{Cl}$ & $\mathrm{Cl}$ & $\mathrm{Ph}$ & $\mathrm{C}_{21} \mathrm{H}_{11} \mathrm{~N}_{2} \mathrm{Cl}_{2} \mathrm{O}$ & $130-132$ & 73 & 91 & $"$ \\
\hline $\mathrm{AS}_{3}$ & $\mathrm{~F}$ & $\mathrm{Br}$ & $\mathrm{Ph}$ & $\mathrm{C}_{2 !} \mathrm{H}_{11} \mathrm{~N}_{2} \mathrm{FBrO}$ & 190-194 & 68 & 90 & $"$ \\
\hline $\mathrm{AS}_{4}$ & $\mathrm{Br}$ & $\mathrm{Br}$ & $\mathrm{Ph}$ & $\mathrm{C}_{21} \mathrm{H}_{11} \mathrm{~N}_{2} \mathrm{Br}_{2} \mathrm{O}$ & 124-128 & 63 & 93 & $"$ \\
\hline $\mathrm{AS}_{5}$ & $\mathrm{Br}$ & $\mathrm{Cl}$ & $\mathrm{Ph}$ & $\mathrm{C}_{21} \mathrm{H}_{11} \mathrm{~N}_{2} \mathrm{BrClO}$ & $160-162$ & 69 & 89 & $"$ \\
\hline $\mathrm{BS}_{6}$ & $\mathrm{H}$ & $\mathrm{H}$ & $\mathrm{Ph}$ & $\mathrm{C}_{21} \mathrm{H}_{18} \mathrm{~N}_{2}$ & $138-140$ & 84 & 92 & $"$ \\
\hline $\mathrm{BS}_{7}$ & $\mathrm{H}$ & $3-F$ & $\mathrm{Ph}$ & $\mathrm{C}_{21} \mathrm{H}_{17} \mathrm{~N}_{2} \mathrm{~F}$ & $122-126$ & 63 & 92 & $"$ \\
\hline $\mathrm{BS}_{8}$ & $\mathrm{H}$ & $3-\mathrm{NO}_{2}$ & $\mathrm{Ph}$ & $\mathrm{C}_{21} \mathrm{H}_{17} \mathrm{~N}_{3} \mathrm{O}_{2}$ & $118-120$ & 73 & 88 & $"$ \\
\hline $\mathrm{BS}_{9}$ & $\mathrm{H}$ & $4-\mathrm{Cl}$ & $\mathrm{Ph}$ & $\mathrm{C}_{21} \mathrm{H}_{17} \mathrm{~N}_{2} \mathrm{Cl}$ & $180-182$ & 78 & 93 & $"$ \\
\hline $\mathrm{BS}_{10}$ & $\mathrm{H}$ & $4-\mathrm{OCH}_{3}$ & $\mathrm{Ph}$ & $\mathrm{C}_{21} \mathrm{H}_{20} \mathrm{~N}_{2} \mathrm{O}$ & $328-330$ & 81 & 91 & $"$ \\
\hline $\mathrm{BS}_{11}$ & $\mathrm{H}$ & 2-Cl & $\mathrm{Ph}$ & $\mathrm{C}_{21} \mathrm{H}_{17} \mathrm{~N}_{2} \mathrm{Cl}$ & $130-132$ & 73 & 86 & $"$ \\
\hline $\mathrm{BS}_{12}$ & $\mathrm{H}$ & $4-\mathrm{CH}_{3}$ & $\mathrm{Ph}$ & $\mathrm{C}_{22} \mathrm{H}_{20} \mathrm{~N}_{2}$ & $128-130$ & 77 & 84 & $"$ \\
\hline $\mathrm{BS}_{13}$ & $\mathrm{H}$ & $4-\mathrm{N}\left(\mathrm{CH}_{3}\right)_{2}$ & $\mathrm{Ph}$ & $\mathrm{C}_{23} \mathrm{H}_{23} \mathrm{~N}_{3}$ & $136-138$ & 59 & 89 & $"$ \\
\hline $\mathrm{CS}_{14}$ & $\mathrm{H}$ & $\mathrm{H}$ & 2,4-DNP & $\mathrm{C}_{21} \mathrm{H}_{16} \mathrm{~N}_{4} \mathrm{O}_{4}$ & $260-262$ & 79 & 90 & $"$ \\
\hline $\mathrm{CS}_{15}$ & $\mathrm{H}$ & $4-\mathrm{OCH}_{3}$ & 2,4-DNP & $\mathrm{C}_{22} \mathrm{H}_{18} \mathrm{~N}_{4} \mathrm{O}_{5}$ & $190-192$ & 69 & 96 & $"$ \\
\hline $\mathrm{CS}_{16}$ & $\mathrm{H}$ & $4-\mathrm{N}\left(\mathrm{CH}_{3}\right)_{2}$ & 2,4-DNP & $\mathrm{C}_{23} \mathrm{H}_{21} \mathrm{~N}_{5} \mathrm{O}_{4}$ & $210-212$ & 68 & 98 & $"$ \\
\hline $\mathrm{CS}_{17}$ & $\mathrm{H}$ & $3-\mathrm{NO}_{2}$ & 2,4-DNP & $\mathrm{C}_{21} \mathrm{H}_{15} \mathrm{~N}_{5} \mathrm{O}_{6}$ & $280-282$ & 75 & 95 & $"$ \\
\hline $\mathrm{CS}_{18}$ & $\mathrm{H}$ & 4-Cl & 2,4-DNP & $\mathrm{C}_{21} \mathrm{H}_{15} \mathrm{~N}_{4} \mathrm{O}_{4} \mathrm{Cl}$ & $268-270$ & 79 & 92 & $"$ \\
\hline $\mathrm{DS}_{19}$ & $\mathrm{H}$ & $\mathrm{H}$ & $\mathrm{H}_{2} \mathrm{~N}-\mathrm{CO}$ & $\mathrm{C}_{16} \mathrm{H}_{15} \mathrm{~N}_{3} \mathrm{O}$ & $168-170$ & 77 & 85 & $"$ \\
\hline $\mathrm{DS}_{20}$ & $\mathrm{H}$ & $4-\mathrm{OCH}_{3}$ & $\mathrm{H}_{2} \mathrm{~N}-\mathrm{CO}$ & $\mathrm{C}_{17} \mathrm{H}_{17} \mathrm{~N}_{3} \mathrm{O}$ & $210-212$ & 86 & 97 & $"$ \\
\hline $\mathrm{DS}_{21}$ & $\mathrm{H}$ & $4-\mathrm{Cl}$ & $\mathrm{H}_{2} \mathrm{~N}-\mathrm{CO}$ & $\mathrm{C}_{16} \mathrm{H}_{14} \mathrm{~N}_{3} \mathrm{ClO}$ & $220-222$ & 89 & 96 & $"$ \\
\hline $\mathrm{DS}_{22}$ & $\mathrm{H}$ & $3-\mathrm{NO}_{2}$ & $\mathrm{H}_{2} \mathrm{~N}-\mathrm{CO}$ & $\mathrm{C}_{16} \mathrm{H}_{14} \mathrm{~N}_{4} \mathrm{O}_{3}$ & $132-134$ & 90 & 94 & $"$ \\
\hline
\end{tabular}

* = Recrystallization solvent

\section{Antibacterial Activity Analysis}

Synthesized compound were tested for their antibacterial activity by adopting agar well diffusion method [21] Bacteria cultures used were Escherichia coli, Bacillus subtillus, Pseudomona pickitii, Enterobacter aerogenes and Micrococcus luteus Roxithromycin was used as standard drug. Using micropipette, $100 \mu \mathrm{l}$ of test solution was poured in respective well. Different concentrations of test samples, a solution for positive control (Roxithromycin) and one for negative control (DMSO) was applied to each Petri plate. These plates were incubated at $37^{\circ} \mathrm{C}$. After 24 hours and 48 hours of incubation the diameter of the clear zones, showing no bacterial growth, around each well was measured. Triplicate plates were prepared for each sample compound. Mean clear zone of these plates was calculated in $\mathrm{mm}$ with standard deviation.

\section{Antifungal Activity Analysis}

Synthesized compound were tested for their antibacterial activity by adopting agar tube dilution method ${ }^{\text {[22]. Fungal }}$ cultures used were Trichphyton longifusus, Candida albicans, Aspergillus flavus, Microsporum canis, Fusarium solani and Candida glabrata. Amphotericin B for Aspergillus flavus and Miconazole for rest of fungal species were used as standard drugs. Tubes are allowed to cool to $50 \mathrm{c}$ and non solidified sabourtaud agar media were poisoned with $66.6 \mathrm{ml}$ of compound pipetted from the stock solution. This will give the final of concentration of $400 \mu \mathrm{g} / \mathrm{ml}$ and $200 \mu \mathrm{g} / \mathrm{ml}$ of the sample and pure compound respectively in media. Tubes were then allowed to solidify in stated position at room temperature. Each tube is inoculated with a $4 \mathrm{~mm}$ diameter piece of inoculums removed from a seven day old culture of fungi. For non-mycelia growth an agar surface streak is employed. Other media supplemented with, DMSO and reference antifungal drug serving as negative and positive control respectively. The tubes incubated at $27-29 \mathrm{c}$ for $7-10$ days. Growth in compound amended media is determined by measuring linear growth $(\mathrm{mm})$ and growth inhibition calculated with reference of negative control.

Percentage inhibition of fungal growth $=100$ - (linear growth in test $(\mathrm{mm}) /$ Linear growth in control $(\mathrm{mm})) \times 100$ 
Structure Activity Relationship

It is observed that among different pyrazolines the presence of various substituents and their positions are very important from biological activity point of view. It was observed that almost all pyrazolines show significant antibacterial activity. Pyrazolines $\mathbf{C S}_{16}, \mathbf{C S}_{17} \& \mathbf{C S}_{19}$ were found to be significantly active against Micrococcus luteus and Enterobacter aerogenes bacterial strains (Table-2).

Table-2 : Antibacterial activity of pyrazolines (AS1-DS23) against five strains.

\begin{tabular}{|c|c|c|c|c|c|c|}
\hline \multirow{2}{*}{ Compound } & \multicolumn{5}{|c|}{ Zone of Inhibition (mm) } & Remarks/ \\
\cline { 2 - 6 } & E.coli & B. subtillus & P. pickitii & M.luteus & E. aerogenes & Activity \\
\hline $\mathbf{R O X}^{*}$ & 25 & 22 & 33 & 22.5 & 20 & Significant \\
\hline $\mathbf{A S}_{1}$ & - & - & 12 & - & - & - \\
\hline $\mathrm{AS}_{2}$ & - & - & - & - & - & - \\
\hline $\mathrm{AS}_{3}$ & - & - & 10 & - & - & - \\
\hline $\mathrm{AS}_{4}$ & - & - & - & 12.5 & 13.5 & - \\
\hline $\mathrm{AS}_{5}$ & - & - & - & - & - & - \\
\hline $\mathrm{BS}_{6}$ & - & - & 11.5 & - & - & - \\
\hline $\mathrm{BS}_{7}$ & - & - & 12 & - & - & - \\
\hline $\mathrm{BS}_{8}$ & - & 13 & 12 & 13.5 & - & - \\
\hline $\mathrm{BS}_{9}$ & 10.35 & - & - & - & - & - \\
\hline $\mathrm{BS}_{10}$ & - & - & - & - & - & - \\
\hline $\mathrm{BS}_{11}$ & - & - & 11 & - & 11.75 & - \\
\hline $\mathrm{BS}_{12}$ & - & - & - & - & - & - \\
\hline $\mathrm{BS}_{13}$ & - & - & - & - & - & - \\
\hline $\mathrm{CS}_{14}$ & - & - & 12 & - & - & - \\
\hline $\mathrm{CS}_{15}$ & 10.5 & 10 & 12.5 & 13.5 & 11.5 & - \\
\hline $\mathrm{CS}_{16}$ & 13 & 11 & 16.25 & 14.5 & 12.5 & - \\
\hline $\mathrm{CS}_{17}$ & - & - & 11.5 & - & 11 & - \\
\hline $\mathrm{CS}_{18}$ & - & 11 & 11.5 & 12.5 & 11.5 & - \\
\hline $\mathrm{DS}_{19}$ & - & - & 11 & - & 11.25 & - \\
\hline $\mathrm{DS}_{20}$ & - & - & - & - & - & - \\
\hline $\mathrm{DS}_{21}$ & - & - & 11.5 & - & - & - \\
\hline $\mathrm{DS}_{22}$ & - & - & - & - & - & - \\
\hline & & & & & & \\
\hline
\end{tabular}

However, the same pyrazolines exhibited significant antibacterial activity against Escherichia coli, Bacillus subtillus and Pseudomonas pickitti as compared to standard drug Roxithromycin. All of other pyrazolines showed mild activity only against Pseudomonas pickitti. The antibacterial exhibited by 2-pyrazolines $\mathbf{C S}_{16}, \mathbf{C S}_{17}$ and $\mathbf{C S}_{19}$ is probably due to the presence of the nitro groups of the 2,4-dinitrophenylhydrazine as well as the presence of a substituents at position 4 of the phenyl ring attached at position 5 of the 2-pyrazoline.However, significant antifungal activity was recorded against two fungal strains i.e. T.longifusus and M.canis (Table-3)

Table-3 : Antifungal activity of pyrazolines (2f-o) against six fungal strains.

\begin{tabular}{|c|c|c|c|c|c|c|c|}
\hline \multirow{2}{*}{ Compound } & \multicolumn{6}{|c|}{$\%$ Inhibition } & \multirow{2}{*}{$\begin{array}{c}\text { Remarks/ } \\
\text { Activity }\end{array}$} \\
\hline & T.longifusus & C.albicans & A.flavus & M.canis & F.solani & C.glabrata & \\
\hline$\overline{\mathrm{AS}_{1}}$ & 85 & 0 & 75 & 80 & 50 & 0 & Significant \\
\hline$\overline{\mathrm{AS}_{3}}$ & 20 & 0 & 90 & 60 & 50 & 0 & $"$ \\
\hline $\mathrm{BS}_{6}$ & 90 & 0 & 70 & 20 & 85 & 0 & $"$ \\
\hline $\mathrm{BS}_{7}$ & 85 & 0 & 0 & 80 & 75 & 0 & $"$ \\
\hline $\mathrm{BS}_{9}$ & 70 & 0 & 50 & 85 & 0 & 0 & $"$ \\
\hline $\mathrm{CS}_{14}$ & 80 & 0 & 20 & 60 & 0 & 0 & $"$ \\
\hline $\mathrm{DS}_{19}$ & 85 & 0 & 0 & 80 & 70 & 0 & $"$ \\
\hline
\end{tabular}

* \% inhibition of standard drug (Miconazole) is $\mathbf{1 0 0 \%}$

In addition, pyrazolines $\left(\mathbf{A S}_{1}, \mathbf{A S}_{\mathbf{3}}\right.$ and $\left.\mathbf{B S}_{6}\right)$ were found significantly active against $A$.flavus. Similarly pyrazolines $\left(\mathbf{B S}_{6}, \mathbf{B S}_{7}\right.$ and $\left.\mathbf{D S}_{19}\right)$ showed considerable activity against $F$.solani. On the other hand, all pyrazolines did not show 
any activity against $C$.albicans and $C$.glabrata fungal strains. In view of structure activity relationship, it can be said that all pyrazolines with any substitution pattem will always show significant antifungal activity against $T$.longifusus and $M$ canis. Against Aflavus 1,3,5 triphenyl pyrazoline $\left(\mathbf{B S}_{6}\right)$ shows moderate activity. When hydrogen atom at position $\mathrm{x}, \mathrm{y}$ and $\mathrm{z}$ are replaced by $\mathrm{Br}, \mathrm{F}$ and $\mathrm{OH}\left(\mathbf{A S}_{\mathbf{l}}\right)$ respectively, no significant change in antifungal activity occurs. But, when the positions of $\mathrm{Br}$ and $\mathrm{F}$ are altered $\left(\mathrm{AS}_{3}\right)$ the activity enhances substantially. Against $F$.solani pyrazoline $\mathbf{B S}_{6}$ showed slightly more activity than against $A$.flavus.

\section{Conclusions}

Synthesis of 2-pyrazolines was carried out with the substitutions of various halogens, hydrazines, hydrazides and semicarbazides at various positions. The ten synthesized pyrazolines were checked for their antibacterial and antifungal activities. It is concluded from the results that 2-pyrazolines are significantly active against all fungal strains accept C.albican and C.glabrata. In contrast to this Pyrazolines $\mathrm{CS}_{16}, \mathrm{CS}_{17} \& \mathrm{CS}_{19}$ were found to be significantly active against Micrococcus luteus and Enterobacter aerogenes bacterial strains. However, the same pyrazolines exhibited significant antibacterial activity against Escherichia coli, Bacillus subtillus and Pseudomonas pickitti as compared to standard drug Roxithromycin. All of other pyrazolines showed mild activity only against Pseudomonas pickitti. The antibacterial exhibited by 2-pyrazolines $\mathbf{C S}_{16}, \mathbf{C S}_{17}$ and $\mathbf{C S}_{19}$ is probably due to the presence of the nitro groups of the 2,4-dinitrophenylhydrazine as well as the presence of a substituents at position 4 of the phenyl ring attached at position 5 of the 2-pyrazoline.

\section{Experimental Protocol}

All melting points were determined in open capillaries using Gallenkemp melting point apparatus and are uncorrected. All chemicals were supplied by Sigma-Aldarich (Germany). $\mathbf{R}_{\mathbf{f}}$ values were calculated by using precoated silica gel aluminum backed thin layer chromatographic (TLC) plates Kieselgel $60 \mathrm{~F}_{254}$ Merck (Germany), in ethyl acetate: pet-ether (1:9). FTIR spectra were recorded on Bio-Rad Merlin using $\mathrm{KBr}$ discs. ' $\mathrm{H}$ NMR spectra were recorded on GEQE 3400, $400 \mathrm{MHz}$ Spectrometer (Oxford Magnet) using TMS as internal standard. EIMS were recorded on VG: 70 SE Mass Spectrometer. Purity of each compound was monitored by TLC. Chemical analyses were carried out on Leco CHNS-932 instrument.

Synthesis of 1,3 diphenyl-2-propen-1-ones $\left(S_{1}-S_{13}\right)$

1, 3-Diphenyl-2-propen-1-one (chalcone) derivatives were synthesized by condensing acetophenone $(0.01 \mathrm{~mol})$ with appropriate benzaldehyde derivatives $(0.01 \mathrm{~mol})$ according to claisen Schmidt condensation ${ }^{[23.25]}$.

\section{General procedure for the Synthesis of 2-pyrazolines $\left(\mathrm{AS}_{1}-\mathrm{DS}_{22}\right)$}

Phenyl hydrazine and /or hydrazide $(0.013 \mathrm{~mol}) 1.33 \mathrm{ml}$ was added to 1-(5-X-2'-hydroxyphenyl)-3-(4-halo)-2propene-1-one $\left(\mathbf{S}_{1}\right)(0.01 \mathrm{~mol}) 3.21 \mathrm{~g}$ in acetic acid $(15 \mathrm{ml})$ and the mixture was refluxed under constant stirring for 3 hours at $100-110^{\circ} \mathrm{C}$ until the cyclization is completed and a deep orange colour developed. The reaction mixture was diluted with ice-cold water. The new thing in this method is the use of extraction step which has been done in ethyl acetate. Removal of the solvent under reduced pressure afforded the product which was purified by crystallization from ethanol. Spectroscopic data of the compounds $\left(\mathbf{A} \mathbf{S}_{1}-\mathbf{D S}_{22}\right)$ are given below.

1-Phenyl-3-(2-hydroxy-5-bromo-phenyl)-5-(4-flouro-phenyl)-2-pyrazolines $\left(\mathrm{AS}_{1}\right)$ IR $(\mathrm{KBr})\left(\mathrm{v}_{\max } / \mathrm{cm}^{\mathrm{l}}\right): 1584$ $(\mathrm{C}=\mathrm{N}), 3028\left(\mathrm{CH}_{2}\right), 1285(\mathrm{C}-\mathrm{N}), 1493\left(\mathrm{C}=\mathrm{C}\right.$ Ar.), $3493(\mathrm{OH}), 630(\mathrm{C}-\mathrm{Br}), 1160(\mathrm{C}-\mathrm{F})$; ${ }^{1} \mathrm{HNMR}\left(\mathrm{CDCl}_{3}\right) \delta \mathrm{H}$ : 3.20 (dd, $1 \mathrm{H}, J=7.40,17.2 \mathrm{~Hz}, \mathrm{H}_{\mathrm{A}}$ ), 3.92(dd, $1 \mathrm{H}, J=12.36,17.2 \mathrm{~Hz}, \mathrm{H}_{\mathrm{B}}$ ), 5.25 (dd, $1 \mathrm{H}, J=7.41,12.2 \mathrm{~Hz}, \mathrm{H}_{\mathrm{X}}$ ), 6.76-7-35

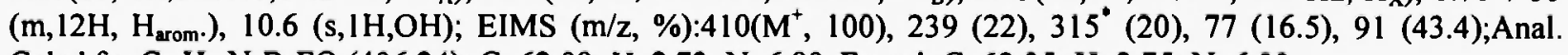
Calcd for $\mathrm{C}_{21} \mathrm{H}_{11} \mathrm{~N}_{2} \mathrm{BrFO}(406.24)$ : C, 62.09; $\mathrm{H}, 2.73 ; \mathrm{N}, 6.90$. Found: $\mathrm{C}, 62.05 ; \mathrm{H}, 2.75 ; \mathrm{N}, 6.93$.

1-Phenyl-3-(2-hydroxy-5-chloro-phenyl)-5-(4-chloro-phenyl)-2-pyrazolines $\left(\mathbf{A S} S_{2}\right)$ IR $(\mathrm{KBr})\left(v_{\max } / \mathrm{cm}^{\mathrm{l}}\right): 1590$ $(\mathrm{C}=\mathrm{N}), 3010\left(\mathrm{CH}_{2}\right), 1280(\mathrm{C}-\mathrm{N}), 1475(\mathrm{C}=\mathrm{C} \mathrm{Ar}), 3500(\mathrm{OH}), 730(\mathrm{C}-\mathrm{Cl})$; ${ }^{1} \mathrm{HNMR}\left(\mathrm{CDCl}_{3}\right) \delta \mathrm{H}: 3.17(\mathrm{dd}$, $\left.1 \mathrm{H}, J=7.40,17.2 \mathrm{~Hz}, \mathrm{H}_{\mathrm{A}}\right), 3.87\left(\mathrm{dd}, 1 \mathrm{H}, J=12.30,17.21 \mathrm{~Hz}, \mathrm{H}_{\mathrm{B}}\right), 5.20\left(\mathrm{dd}, 1 \mathrm{H}, J=7.40,12.1 \mathrm{~Hz}, \mathrm{H}_{\mathrm{X}}\right), 6.56-7.71(\mathrm{~m}, 12 \mathrm{H}$, $\left.\mathrm{H}_{\text {arom. }}\right), 10.6(\mathrm{~s}, \mathrm{IH}, \mathrm{OH})$; EIMS (m/z, \%): $382^{\circ}\left(\mathrm{M}^{+}, 100\right), 255^{*}(30), 271^{*}(18), 77(18), 91$ (40) :Anal. Calcd for $\mathrm{C}_{21} \mathrm{H}_{11} \mathrm{~N}_{2} \mathrm{Cl}_{2} \mathrm{O}$ (378.24): C, 66.69; H, 2.93; N, 7.41. Found: C, 66.66; H, 2.95; N, 7.43.

I-Phenyl-3-(2-hydroxy-5-fluoro-phenyl)-5-(4-bromo-phenyl)-2-pyrazolines $\left(\mathrm{AS}_{3}\right) \mathrm{IR}(\mathrm{KBr})\left(\mathrm{v}_{\max } / \mathrm{cm}^{\mathrm{l}}\right): 1580$ $(\mathrm{C}=\mathrm{N}), 3015\left(\mathrm{CH}_{2}\right), 1290(\mathrm{C}-\mathrm{N}), 1480(\mathrm{C}=\mathrm{C} \mathrm{Ar}), 3495(\mathrm{OH}), 1170(\mathrm{C}-\mathrm{F}), 640(\mathrm{C}-\mathrm{Br})$; ${ }^{1} \mathrm{HNMR}\left(\mathrm{CDCl}_{3}\right) \delta \mathrm{H}$ : $3.2 \mathrm{l}\left(\mathrm{dd}, 1 \mathrm{H}, J=7.39,17.2 \mathrm{~Hz}, \mathrm{H}_{\mathrm{A}}\right), 3.94\left(\mathrm{dd}, \mathrm{lH}, J=12.34,17.2 \mathrm{~Hz}, \mathrm{H}_{\mathrm{B}}\right), 5.27\left(\mathrm{dd}, \mathrm{lH}, J=7.41,12.2 \mathrm{~Hz}, \mathrm{H}_{\mathrm{X}}\right), 6.62-7.54$ 
$\left(\mathrm{m}, 12 \mathrm{H}, \mathrm{H}_{\text {arom }}\right), 10.7(\mathrm{~s}, 1 \mathrm{H}, \mathrm{OH})$; EIMS (m/z, \%):410 (100), 299* (40), 255 (20), 77 (19), 91 (35) ;Anal. Calcd for $\mathrm{C}_{21} \mathrm{H}_{11} \mathrm{~N}_{2} \mathrm{FBrO}$ (406.24): C, 62.06; H, 2.74; N, 6.91. Found: C, 62.04; H, 2.72; N, 6.94 .

1-Phenyl-3-(2-hydroxy-5-bromo-phenyl)-5-(4-bromo-phenyl)-2-pyrazolines $\left(\mathrm{AS}_{4}\right) \quad \mathrm{IR}(\mathrm{KBr})\left(\mathrm{v}_{\max } / \mathrm{cm}^{\mathrm{l}}\right) 1583$ $(\mathrm{C}=\mathrm{N}), 3019\left(\mathrm{CH}_{2}\right), 1282(\mathrm{C}-\mathrm{N}), 1495(\mathrm{C}=\mathrm{C}$ Ar. $), 3480(\mathrm{OH}), 650(\mathrm{C}-\mathrm{Br}){ }^{1} \mathrm{HNMR}\left(\mathrm{CDCl}_{3}\right) \delta \mathrm{H}: 3.18(\mathrm{dd}$, $\left.1 \mathrm{H}, J=7.41,17.2 \mathrm{~Hz}, \mathrm{H}_{\mathrm{A}}\right), 3.90\left(\mathrm{dd}, 1 \mathrm{H}, J=12.35,17.1 \mathrm{~Hz}, \mathrm{H}_{\mathrm{B}}\right), 5.23\left(\mathrm{dd}, 1 \mathrm{H}, J=7.41,12.2 \mathrm{~Hz}, \mathrm{H}_{\mathrm{X}}\right), 6.70-7.32(\mathrm{~m}, 12 \mathrm{H}$, $\left.\mathrm{H}_{\text {arom }}\right), 10.6(\mathrm{~s}, 1 \mathrm{H}, \mathrm{OH})$; EIMS $(\mathrm{m} / \mathrm{z}, \%): 470^{* *}\left(\left(\mathrm{M}^{+}, 100\right), 299^{*}(38), 315^{*}(22), 77\right.$ (22), 91 (40) ;Anal. Calcd for $\mathrm{C}_{21} \mathrm{H}_{11} \mathrm{~N}_{2} \mathrm{Br}_{2} \mathrm{O}(467.14)$ : C, 54.00; $\mathrm{H}, 2.37 ; \mathrm{N}, 6.00$. Found: $\mathrm{C}, 54.05 ; \mathrm{H}, 2.35 ; \mathrm{N}, 6.03$.

1-Phenyl-3-(2-hydroxy-5-bromo-phenyl)-5-(4-chloro-phenyl)-2-pyrazolines $\left(\mathbf{A S}_{5}\right)$ IR $(\mathrm{KBr})\left(v_{\max } / \mathrm{cm}^{\prime}\right): 1595$ $(\mathrm{C}=\mathrm{N}), 3035\left(\mathrm{CH}_{2}\right), 1292(\mathrm{C}-\mathrm{N}), 1494\left(\mathrm{C}=\mathrm{C}\right.$ Ar.), $3520(\mathrm{OH}), 660(\mathrm{C}-\mathrm{Br}), 750(\mathrm{C}-\mathrm{Cl}) ;{ }^{1} \mathrm{HNMR}\left(\mathrm{CDCl}_{3}\right) \delta \mathrm{H}$ : 3.19 (dd, $1 \mathrm{H}, J=7.40,17.21 \mathrm{~Hz}, \mathrm{H}_{\mathrm{A}}$ ), 3.89(dd, $1 \mathrm{H}, J=12.36,17.2 \mathrm{~Hz}, \mathrm{H}_{\mathrm{B}}$ ), $5.21\left(\mathrm{dd}, 1 \mathrm{H}, J=7.41,12.1 \mathrm{~Hz}, \mathrm{H}_{\mathrm{X}}\right), 6.69-7.60$ $\left(\mathrm{m}, 12 \mathrm{H}, \mathrm{H}_{\text {arom }}\right), 10.4(\mathrm{~s}, 1 \mathrm{H}, \mathrm{OH})$; EIMS (m/z, \%): 426"* $\left(\mathrm{M}^{+}, 100\right), 255^{*}(30), 315^{*}(32), 77$ (16), 91 (60) ;Anal. Calcd for $\mathrm{C}_{21} \mathrm{H}_{11} \mathrm{~N}_{2} \mathrm{BrClO}$ (422.69): C, 59.67; H, 2.62; N, 6.63. Found: $\mathrm{C}, 59.65 ; \mathrm{H}, 2.65 ; \mathrm{N}, 6.60$.

1, 3, 5-Triphenyl-2-pyrazolines $\left(\mathrm{BS}_{6}\right)$ IR $(\mathrm{KBr})\left(\mathrm{v}_{\max } / \mathrm{cm}^{\mathrm{l}}\right)$ : $1595(\mathrm{C}=\mathrm{N}), 2908\left(\mathrm{CH}_{2}\right), 1239(\mathrm{C}-\mathrm{N}), 1491(\mathrm{C}=\mathrm{C}$ Ar. $)$; 'HNMR $\left(\mathrm{CDCl}_{3}\right) \delta \mathrm{H}: 3.16\left(\mathrm{dd}, 1 \mathrm{H}, J=7.24,17.02 \mathrm{~Hz}, \mathrm{H}_{\mathrm{A}}\right), 3.86\left(\mathrm{dd}, 1 \mathrm{H}, J=12.3,17.02 \mathrm{~Hz}, \mathrm{H}_{\mathrm{B}}\right), 5.28(\mathrm{dd}, 1 \mathrm{H}, J=$ $7.24,12.33 \mathrm{~Hz}, \mathrm{HX}), 6.76-7.71\left(\mathrm{~m}, 15 \mathrm{H}, \mathrm{H}_{\text {arom }}\right)$; EIMS (m/z, \%): $298\left(\mathrm{M}^{+}, 100\right), 221$ (45.2), 194 (10.6), 91 (42.6), 77 (13.4) ;Anal. Calcd for $\mathrm{C}_{21} \mathrm{H}_{18} \mathrm{~N}_{2}$ (298.39): C, 84.53; H, 6.08; N, 9.39. Found: C, 84.55; H, 6.10; N, 9.36.

1, 3-Diphenyl-5-(3-fluoro-phenyl)-2-pyrazolines $\left(\mathrm{BS}_{7}\right) \mathrm{IR}(\mathrm{KBr})\left(\mathrm{v}_{\max } / \mathrm{cm}^{\prime}\right): 1570(\mathrm{C}=\mathrm{N}), 3010\left(\mathrm{CH}_{2}\right), 1241(\mathrm{C}-$ $\mathrm{N}), 1470\left(\mathrm{C}=\mathrm{C}\right.$ Ar.), $1125(\mathrm{C}-\mathrm{F})$; ${ }^{1} \mathrm{HNMR}\left(\mathrm{CDCl}_{3}\right) \delta \mathrm{H}: 3.12\left(\mathrm{dd}, 1 \mathrm{H}, J=7.14,17.05 \mathrm{~Hz}, \mathrm{H}_{\mathrm{A}}\right), 3.85(\mathrm{dd}, 1 \mathrm{H}, J$ $\left.=12.32,17.04 \mathrm{~Hz}, \mathrm{H}_{\mathrm{B}}\right), 5.27(\mathrm{dd}, 1 \mathrm{H}, J=7.1,12.2 \mathrm{~Hz}, \mathrm{HX}), 6.77-7.71\left(\mathrm{~m}, 14 \mathrm{H}, \mathrm{H}_{\text {arom }}\right) ;$ EIMS $(\mathrm{m} / \mathrm{z}, \%): 316\left(\mathrm{M}^{+}\right.$, 100), 221 (57), 194 (19.7), 91 (83.4), 77 (19.9) ;Anal. Calcd for $\mathrm{C}_{21} \mathrm{H}_{17} \mathrm{~N}_{2} \mathrm{~F}$ (316.38): C, 79.72; H, 5.42; N, 8.85. Found: $\mathrm{C}, 79.75 ; \mathrm{H}, 5.45 ; \mathrm{N}, 8.82$.

1, 3-Diphenyl-5-(3-nitro-phenyl)-2-pyrazolines $\left(\mathrm{BS}_{8}\right)$ IR $(\mathrm{KBr})\left(\mathrm{v}_{\max } / \mathrm{cm}^{\prime}\right): 1580(\mathrm{C}=\mathrm{N}), 3025\left(\mathrm{CH}_{2}\right), 1250(\mathrm{C}-\mathrm{N})$, $1495\left(\mathrm{C}=\mathrm{C}\right.$ Ar.), $1325(\mathrm{C}-\mathrm{N})$; ${ }^{1} \mathrm{HNMR}\left(\mathrm{CDCl}_{3}\right) \delta \mathrm{H}: 3.13\left(\mathrm{dd}, 1 \mathrm{H}, J=7.14,17.04 \mathrm{~Hz}, \mathrm{H}_{\mathrm{A}}\right), 3.89(\mathrm{dd}, \mathrm{IH}, J=12.3,17.03$ $\left.\mathrm{Hz}, \mathrm{H}_{\mathrm{B}}\right), 5.29$ (dd, $\left.1 \mathrm{H} J=7.1,12.2 \mathrm{~Hz}, \mathrm{HX}\right), 6.79-7.71\left(\mathrm{~m}, 14 \mathrm{H}, \mathrm{H}_{\text {arom }}\right.$ ); EIMS (m/z, \%): $343\left(\mathrm{M}^{+}, 100\right), 221(52)$, 194 (20), 91 (74), 77 (12.2) ;Anal. Calcd for $\mathrm{C}_{21} \mathrm{H}_{17} \mathrm{~N}_{3} \mathrm{O}_{2}$ (343.39): C, 73.45; H, 4.99; N, 12.24. Found: C, 73.42; $\mathrm{H}$, $4.95 ; \mathrm{N}, 12.22$.

1, 3-Diphenyl-5-(4-chloro-phenyl)-2-pyrazolines (BS9) IR $(\mathrm{KBr})\left(\mathrm{v}_{\max } / \mathrm{cm}^{\mathrm{l}}\right): 1590(\mathrm{C}=\mathrm{N}), 3010\left(\mathrm{CH}_{2}\right), 1237(\mathrm{C}$ $\mathrm{N}), 1475(\mathrm{C}=\mathrm{C}$ Ar. $), 692(\mathrm{C}-\mathrm{Cl})$; $\mathrm{HNMR}\left(\mathrm{CDCl}_{3}\right) \delta \mathrm{H}: 3.1 \mathrm{I}\left(\mathrm{dd}, 1 \mathrm{H}, J=7.3,17.03 \mathrm{~Hz}, \mathrm{H}_{\mathrm{A}}\right), 3.86(\mathrm{dd}, 1 \mathrm{H}, J$ $\left.=12.3,17.02 \mathrm{~Hz}, \mathrm{H}_{\mathrm{B}}\right), 5.25(\mathrm{dd}, 1 \mathrm{H}, J=7.13,12.2 \mathrm{~Hz}, \mathrm{HX}), 6.78-8.03\left(\mathrm{~m}, 14 \mathrm{H}, \mathrm{H}_{\text {arom }}\right) ;$ EIMS $(\mathrm{m} / \mathrm{z}, \%): 332^{*}\left(\mathrm{M}^{+}\right.$, 100), 221 (27.8), 194 (9.6), 91 (36.3), 77 (11.3) ;Anal. Calcd for $\mathrm{C}_{21} \mathrm{H}_{17} \mathrm{~N}_{2} \mathrm{Cl}(332.84): \mathrm{C}, 75.78 ; \mathrm{H}, 5.15 ; \mathrm{N}, 8.42$. Found: $\mathrm{C}, 75.76 ; \mathrm{H}, 5.13 ; \mathrm{N}, 8.45$.

1, 3-Diphenyl-5-(4-methoxy-phenyl)-2-pyrazolines $\left(\mathrm{BS}_{10}\right)$ IR $(\mathrm{KBr})\left(v_{\max } / \mathrm{cm}^{\prime}\right): 1595(\mathrm{C}=\mathrm{N}), 3020\left(\mathrm{CH}_{2}\right), 1252$ (C-N), $1477\left(\mathrm{C}=\mathrm{C}\right.$ Ar.), $1155(\mathrm{C}-\mathrm{O}-\mathrm{C})$; ${ }^{1} \mathrm{HNMR}\left(\mathrm{CDCl}_{3}\right) \delta \mathrm{H}: 3.13\left(\mathrm{dd}, 1 \mathrm{H}, J=7.20,17.05 \mathrm{~Hz}, \mathrm{H}_{\mathrm{A}}\right), 3.83(\mathrm{dd}, 1 \mathrm{H}, J$ $\left.=12.37,17.04 \mathrm{~Hz}, \mathrm{H}_{\mathrm{B}}\right), 5.24\left(\mathrm{dd}, 1 \mathrm{H}, J=7.18,12.2 \mathrm{~Hz}, \mathrm{H}_{\mathrm{X}}\right), 6.75-7.71\left(\mathrm{~m}, 14 \mathrm{H}, \mathrm{H}_{\text {arom }}\right), 3.75\left(\mathrm{~s}, 3 \mathrm{H},-\mathrm{OCH}_{3}\right)$; EIMS (m/z, \%): $328\left(\mathrm{M}^{+}, 100\right), 221$ (16.6), 194 (13.1), 91 (40.8);Anal. Calcd for $\mathrm{C}_{21} \mathrm{H}_{20} \mathrm{~N}_{2} \mathrm{O}$ (316.41): C, 79.72; $\mathrm{H}, 6.37$; $\mathrm{N}, 8.85$. Found: $\mathrm{C}, 79.75 ; \mathrm{H}, 6.35 ; \mathrm{N}, 8.80$.

1, 3-Diphenyl-5-(2-chloro-phenyl)-2-pyrazolines $\left(\mathrm{BS}_{11}\right)$ IR $(\mathrm{KBr})\left(\mathrm{v}_{\max } / \mathrm{cm}^{\mathrm{l}}\right): 1585(\mathrm{C}=\mathrm{N}), 3022\left(\mathrm{CH}_{2}\right), 1247(\mathrm{C}-$ N), $1480(\mathrm{C}=\mathrm{C}$ Ar. $), 690(\mathrm{C}-\mathrm{Cl}) ;{ }^{1} \mathrm{HNMR}\left(\mathrm{CDCl}_{3}\right) \delta \mathrm{H}: 3.07\left(\mathrm{dd}, 1 \mathrm{H}, J=6.7,17.20 \mathrm{~Hz}, \mathrm{H}_{\mathrm{A}}\right), 3.99(\mathrm{dd}, 1 \mathrm{H}, J=12.4,17.1$ $\left.\mathrm{Hz}, \mathrm{H}_{\mathrm{B}}\right), 5.65(\mathrm{dd}, 1 \mathrm{H}, J=6.7,12.3 \mathrm{~Hz}, \mathrm{HX}), 6.79-7.72\left(\mathrm{~m}, 14 \mathrm{H}, \mathrm{H}_{\mathrm{arom}}\right)$ ); EIMS $(\mathrm{m} / \mathrm{z}, \%): 332^{\circ}\left(\mathrm{M}^{+}, 100\right), 221(84.7)$, 194 (18.1), 91 (70.3), 77 (22.3) ;Anal. Calcd for $\mathrm{C}_{21} \mathrm{H}_{17} \mathrm{~N}_{2} \mathrm{Cl}$ (332.84): C, 75.77; H, 5.14; N, 8.41. Found: C, 75.79; H, 5.16; N, 8.40.

1, 3-Diphenyl-5-(4-methyl-phenyl)-2-pyrazolines $\left(\mathrm{BS}_{12}\right) \mathrm{IR}(\mathrm{KBr})\left(\mathrm{v}_{\max } / \mathrm{cm}^{\mathrm{l}}\right): 1595(\mathrm{C}=\mathrm{N}), 3035\left(\mathrm{CH}_{2}\right), 1292(\mathrm{C}-$ $\mathrm{N}), 1494(\mathrm{C}=\mathrm{C} \mathrm{Ar}),. 2900\left(\mathrm{CH}_{2}\right)$; ${ }^{\mathrm{H}} \mathrm{HNMR}\left(\mathrm{CDCl}_{3}\right) \delta \mathrm{H}: 3.13\left(\mathrm{dd}, 1 \mathrm{H}, J=7.23,17.04 \mathrm{~Hz}, \mathrm{H}_{\mathrm{A}}\right), 3.84(\mathrm{dd}, 1 \mathrm{H}, J$ $\left.=12.32,17.01 \mathrm{~Hz}, \mathrm{H}_{\mathrm{B}}\right), 5.25\left(\mathrm{dd}, 1 \mathrm{H}, J=7.22,12.2 \mathrm{~Hz}, \mathrm{H}_{\mathrm{X}}\right), 6.71-7.71\left(\mathrm{~m}, 14 \mathrm{H}, \mathrm{H}_{\mathrm{arom}}\right), 2.30\left(\mathrm{~s}, 3 \mathrm{H},-\mathrm{CH}_{3}\right) ;$ EIMS $(\mathrm{m} / \mathrm{z}$, \%): $312\left(\mathrm{M}^{+}, 100\right), 221$ (29), 194 (11.6), 91 (38.1), 77 (21.6);Anal. Calcd for $\mathrm{C}_{22} \mathrm{H}_{20} \mathrm{~N}_{2}$ (312.42): C, 84.58; H, 6.45; $\mathrm{N}, 8.97$. Found: $\mathrm{C}, 84.56 ; \mathrm{H}, 6.44 ; \mathrm{N}, 8.95$. 
1, 3-Diphenyl-5-(4-N-N dimethyl phenyl)-2-pyrazolines $\left(\mathrm{BS}_{13}\right) \mathrm{IR}(\mathrm{KBr})\left(\mathrm{v}_{\max } / \mathrm{cm}^{1}\right): 1575(\mathrm{C}=\mathrm{N}), 3000\left(\mathrm{CH}_{2}\right)$, $1240(\mathrm{C}-\mathrm{N}), 1492\left(\mathrm{C}=\mathrm{C}\right.$ Ar.), $1300\left(\mathrm{~N}_{-} \mathrm{CH}_{3}\right) ;{ }^{1} \mathrm{HNMR}\left(\mathrm{CDCl}_{3}\right) \delta \mathrm{H}: 3.14\left(\mathrm{dd}, 1 \mathrm{H}, J=7.29,16.9 \mathrm{~Hz}, \mathrm{H}_{\mathrm{A}}\right), 3.80(\mathrm{dd}, 1 \mathrm{H}, J$ $\left.=12.2,17.02 \mathrm{~Hz}, \mathrm{H}_{\mathrm{B}}\right), 5.20\left(\mathrm{dd}, 1 \mathrm{H}, J=7.28,12.1 \mathrm{~Hz}, \mathrm{H}_{\mathrm{X}}\right), 6.65-7.71\left(\mathrm{~m}, 14 \mathrm{H}, \mathrm{H}_{\text {arom. }}\right), 2.90\left(\mathrm{~s}, 6 \mathrm{H}, \mathrm{N}\left(\mathrm{CH}_{3}\right)_{2}\right)$; EIMS $(\mathrm{m} / \mathrm{z}, \%): 34 \mathrm{l}\left(\mathrm{M}^{+}, 100\right), 22 \mathrm{l}$ (13.8), 194 (12.2), 91 (22.4), 147 (37.3);Anal. Calcd for $\mathrm{C}_{23} \mathrm{H}_{23} \mathrm{~N}_{3}(341.46)$ : C, 80.90; $\mathrm{H}, 6.79 ; \mathrm{N}, 12.31$. Found: $\mathrm{C}, 80.95 ; \mathrm{H}, 6.75 ; \mathrm{N}, 12.33$.

I-(2, 4-Dinitro phenyl)-3, 5-diphenyl-2-pyrazolines $\left(\mathrm{CS}_{14}\right)$ IR $(\mathrm{KBr})\left(v_{\max } / \mathrm{cm}^{1}\right): 1587(\mathrm{C}=\mathrm{N}), 3104\left(\mathrm{CH}_{2}\right), 1300$ $(\mathrm{C}-\mathrm{N}), 1497\left(\mathrm{C}=\mathrm{C} \mathrm{Ar}\right.$ ); ${ }^{1} \mathrm{HNMR}\left(\mathrm{CDCl}_{3}\right) \delta \mathrm{H}: 3.38\left(\mathrm{dd}, 1 \mathrm{H}, J=5.06,17.1 \mathrm{~Hz}, \mathrm{H}_{\mathrm{A}}\right), 3.95\left(\mathrm{dd}, 1 \mathrm{H}, J=12.1,17.6 \mathrm{~Hz}, \mathrm{H}_{\mathrm{B}}\right)$,

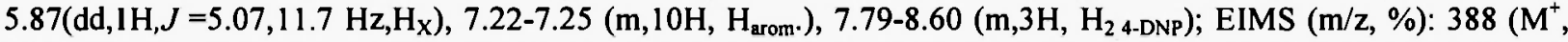
100), 358 (80), 342 (40), 77 (70), 51 (40) ;Anal. Calcd for $\mathrm{C}_{21} \mathrm{H}_{16} \mathrm{~N}_{4} \mathrm{O}_{4}$ (388.39): C, 64.94; H, 4.15; N, 14.43. Found: C, $64.95 ; \mathrm{H}, 4.18 ; \mathrm{N}, 14.46$.

1-(2, 4-Dinitro phenyl) 3-phenyl-5-(4-methoxy-phenyl)-2-pyrazolines $\left(\mathrm{CS}_{15}\right) \mathrm{IR}(\mathrm{KBr})\left(\mathrm{v}_{\max } / \mathrm{cm}^{\mathrm{l}}\right): 1585(\mathrm{C}=\mathrm{N})$, $3105\left(\mathrm{CH}_{2}\right), 1299(\mathrm{C}-\mathrm{N}), 1496\left(\mathrm{C}=\mathrm{C}\right.$ Ar.), $1154(\mathrm{C}-\mathrm{O}-\mathrm{C})$; ${ }^{1} \mathrm{HNMR}\left(\mathrm{CDCl}_{3}\right) \delta \mathrm{H}: 3.39\left(\mathrm{dd}, 1 \mathrm{H}, J=5.06,17.1 \mathrm{~Hz}, \mathrm{H}_{\mathrm{A}}\right)$, $3.90\left(\mathrm{dd}, 1 \mathrm{H}, J=12.2,17.6 \mathrm{~Hz}, \mathrm{H}_{\mathrm{B}}\right), 5.87\left(\mathrm{dd}, 1 \mathrm{H}, J=5.08,11.7 \mathrm{~Hz}, \mathrm{H}_{\mathrm{X}}\right), 7.27-7.29\left(\mathrm{~m}, 9 \mathrm{H}, \mathrm{H}_{\text {arom }}\right), 7.79-8.69\left(\mathrm{~m}, 3 \mathrm{H}, \mathrm{H}_{24}\right.$ DNP), 3.70(s,3H,OCH $)$; $\quad$ EIMS (m/z, \%):418( $\left.\mathrm{M}^{+}, 100\right), 388(78), 372(42), 77(60), 51$ (30) ;Anal. Calcd for $\mathrm{C}_{22} \mathrm{H}_{18} \mathrm{~N}_{4} \mathrm{O}_{5}$ (418.41): C, 63.15; $\mathrm{H}, 4.34 ; \mathrm{N}, 13.39$. Found: $\mathrm{C}, 63.17 ; \mathrm{H}, 4.36 ; \mathrm{N}, 13.36$.

1-(2, 4-Dinitro phenyl) 3-phenyl-5-(4-N-N dimethyl-phenyl)-2-pyrazolines $\left(\mathrm{CS}_{16}\right) \mathrm{IR}(\mathrm{KBr})\left(\mathrm{v}_{\max } / \mathrm{cm}^{\prime}\right): 1570$ $(\mathrm{C}=\mathrm{N}), 3010\left(\mathrm{CH}_{2}\right), 1285(\mathrm{C}-\mathrm{N}), 1490(\mathrm{C}=\mathrm{C} \mathrm{Ar}),. 1325\left(\mathrm{CH}_{3}\right) ;{ }^{1} \mathrm{HNMR}\left(\mathrm{CDCl}_{3}\right) \delta \mathrm{H}: 3.37(\mathrm{dd}, 1 \mathrm{H}, J=5.06,17.1 \mathrm{~Hz}$, $\left.\mathrm{H}_{\mathrm{A}}\right), 3.89\left(\mathrm{dd}, 1 \mathrm{H}, J=12.2,17.6 \mathrm{~Hz}, \mathrm{H}_{\mathrm{B}}\right), 5.82\left(\mathrm{dd}, 1 \mathrm{H}, J=5.09,11.7 \mathrm{~Hz}, \mathrm{H}_{\mathrm{X}}\right), 7.79-7.35\left(\mathrm{~m}, 9 \mathrm{H}, \mathrm{H}_{\text {arom }}\right), 7.79-8.59(\mathrm{~m}, 3 \mathrm{H}$,

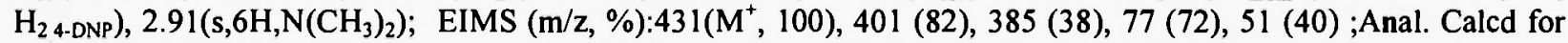
$\mathrm{C}_{23} \mathrm{H}_{21} \mathrm{~N}_{5} \mathrm{O}_{4}$ (431.45): $\mathrm{C}, 64.03 ; \mathrm{H}, 4.91 ; \mathrm{N}, 16.23$. Found: $\mathrm{C}, 64.05 ; \mathrm{H}, 4.95 ; \mathrm{N}, 16.25$.

1-(2, 4-Dinitro phenyl) 3-phenyl-5-(3-nitro-phenyl)-2-pyrazolines $\left(\mathrm{CS}_{17}\right) \mathrm{IR}(\mathrm{KBr})\left(\mathrm{v}_{\max } / \mathrm{cm}^{\mathrm{l}}\right)$ : $1583(\mathrm{C}=\mathrm{N}), 3125$ $\left(\mathrm{CH}_{2}\right), 1302(\mathrm{C}-\mathrm{N}), 1486\left(\mathrm{C}=\mathrm{C}\right.$ Ar.); ${ }^{1} \mathrm{HNMR}\left(\mathrm{CDCl}_{3}\right) \delta \mathrm{H}: 3.35\left(\mathrm{dd}, 1 \mathrm{H}, J=5.06,17.1 \mathrm{~Hz}, \mathrm{H}_{\mathrm{A}}\right), 3.92(\mathrm{dd}, 1 \mathrm{H}, J$ $\left.=12.2,17.6 \mathrm{~Hz}, \mathrm{H}_{\mathrm{B}}\right), 5.86\left(\mathrm{dd}, 1 \mathrm{H}, J=5.09,11.7 \mathrm{~Hz}, \mathrm{H}_{\mathrm{X}}\right), 7.27-7.37\left(\mathrm{~m}, 9 \mathrm{H}, \mathrm{H}_{\text {arom }}\right)$ ) 7.70-8.65(m, 3H, $\mathrm{H}_{2}$ 4-DNP); EIMS (m/z, \%):433( $\left.\mathrm{M}^{+}, 100\right), 403$ (76), $387(46), 77$ (66), 51 (30) ;Anal. Calcd for $\mathrm{C}_{21} \mathrm{H}_{15} \mathrm{~N}_{5} \mathrm{O}_{6}$ (433.38): C, 58.20; $\mathrm{H}$, $3.49 ; \mathrm{N}, 16.16$. Found: $\mathrm{C}, 58.25 ; \mathrm{H}, 3.45 ; \mathrm{N}, 16.19$.

1-(2, 4-Dinitro phenyl) 3-phenyl-5-(4-chloro-phenyl)-2-pyrazolines $\left(\mathrm{CS}_{18}\right) \overline{\mathrm{IR}}(\mathrm{KBr})\left(\mathrm{v}_{\max } / \mathrm{cm}^{\prime}\right): 1599(\mathrm{C}=\mathrm{N})$, $3115\left(\mathrm{CH}_{2}\right), 1310(\mathrm{C}-\mathrm{N}), 1500\left(\mathrm{C}=\mathrm{C} \mathrm{Ar}\right.$ ), $690(\mathrm{C}-\mathrm{Cl}) ;{ }^{1} \mathrm{HNMR}\left(\mathrm{CDCl}_{3}\right) \delta \mathrm{H}: 3.35\left(\mathrm{dd}, 1 \mathrm{H}, J=5.08,17.2 \mathrm{~Hz}, \mathrm{H}_{\mathrm{A}}\right)$, 3.92(dd, $\left.1 \mathrm{H}, J=12.1,17.3 \mathrm{~Hz}, \mathrm{H}_{\mathrm{B}}\right), 5.86\left(\mathrm{dd}, 1 \mathrm{H}, J=5.08,11.6 \mathrm{~Hz}, \mathrm{H}_{\mathrm{X}}\right), 7.27-7.37\left(\mathrm{~m}, 9 \mathrm{H}, \mathrm{H}_{\text {arom }}\right.$ ), 7.70-8.65(m, 3H, $\mathrm{H}_{2,4}$ DNP); EIMS (m/z, \%): $422.5^{\circ}(100), 392^{*}(80), 376^{\circ}(50), 77(74), 51$ (46) ;Anal. Calcd for $\mathrm{C}_{21} \mathrm{H}_{15} \mathrm{~N}_{4} \mathrm{O}_{4} \mathrm{Cl}(422.33)$ : C, $59.65 ; \mathrm{H}, 3.58 ; \mathrm{N}, 13.25$. Found: C, $59.62 ; \mathrm{H}, 3.54 ; \mathrm{N}, 13.22$.

I-Carboxamide-3, 5-diphenyl-2-pyrazolines $\left(\overline{D S}_{19}\right) \overline{I R}(\mathrm{KBr})\left(\mathrm{v}_{\max } / \mathrm{cm}^{\prime}\right): 1584(\mathrm{C}=\mathrm{N}), 3023\left(\mathrm{CH}_{2}\right), 1285(\mathrm{C}-\mathrm{N})$, 1493 (C=C Ar.), $1686(\mathrm{C}=\mathrm{O}), 3493(\mathrm{~N}-\mathrm{H}) ;{ }^{1} \mathrm{HNMR}\left(\mathrm{CDCl}_{3}\right) \delta \mathrm{H}: 3.19$ (dd, $\left.1 \mathrm{H}, J=5.30,17.6 \mathrm{~Hz}, \mathrm{H}_{\mathrm{A}}\right), 3.81(\mathrm{dd}, 1 \mathrm{H}, J$ $\left.=12.02,17.5 \mathrm{~Hz}, \mathrm{H}_{\mathrm{B}}\right), 5.54\left(\mathrm{dd}, 1 \mathrm{H}, J=5.02,11.9 \mathrm{~Hz}, \mathrm{H}_{\mathrm{X}}\right), 7.22-7.69\left(\mathrm{~m}, 10 \mathrm{H}, \mathrm{H}_{\text {arom }}\right), 5.87\left(\mathrm{br} .5,2 \mathrm{H}, \mathrm{NH}_{2}\right) ;$ EIMS $(\mathrm{m} / \mathrm{z}$, \%): $265\left(\mathrm{M}^{+}, 15.6\right), 222(81.9), 144(100), 118(39.2), 104(72.8), 77$ (74), 51(33) ;Anal. Calcd for $\mathrm{C}_{16} \mathrm{H}_{15} \mathrm{~N}_{3} \mathrm{O}$ (265.32): C, 72.43; H, 5.70; N, 15.84. Found: C, 72.45; H, 5.75; N, 15.80.

1-Carboxamide-3-phenyl-5-(4-methoxy-phenyl)-2-pyrazolines $\left(\mathrm{DS}_{20}\right)$ IR $(\mathrm{KBr})\left(\mathrm{v}_{\max } / \mathrm{cm}^{1}\right): 1590(\mathrm{C}=\mathrm{N}), 3030$ $\left(\mathrm{CH}_{2}\right), 1280(\mathrm{C}-\mathrm{N}), 1490\left(\mathrm{C}=\mathrm{C}\right.$ Ar.), $1690(\mathrm{C}=\mathrm{O}), 3455(\mathrm{~N}-\mathrm{H}), 1136(\mathrm{C}-\mathrm{O}-\mathrm{C}) ;{ }^{\mathrm{H}} \mathrm{HNMR}\left(\mathrm{CDCl}_{3}\right) \delta \mathrm{H}: 3.15(\mathrm{dd}, 1 \mathrm{H}, J$ $\left.=5.30,17.6 \mathrm{~Hz}, \mathrm{H}_{\mathrm{A}}\right), 3.80\left(\mathrm{dd}, 1 \mathrm{H}, J=12.06,17.5 \mathrm{~Hz}, \mathrm{H}_{\mathrm{B}}\right), 5.52\left(\mathrm{dd}, 1 \mathrm{H}, J=5.08,12.1 \mathrm{~Hz}, \mathrm{H}_{\mathrm{X}}\right), 718-7.78\left(\mathrm{~m}, 9 \mathrm{H}, \mathrm{H}_{\text {arom }}\right)$, 5.70(br.s, $\left.2 \mathrm{H}_{1} \mathrm{NH}_{2}\right), 3.90\left(\mathrm{~s}, 3 \mathrm{H}, \mathrm{OCH}_{3}\right) ; \operatorname{EIMS}(\mathrm{m} / \mathrm{z}, \%): 295\left(\mathrm{M}^{+}, 20\right), 251(70), 144(100), 118(42), 104(70), 77$ (60), 51 (32) ;Anal. Calcd for $\mathrm{C}_{17} \mathrm{H}_{17} \mathrm{~N}_{3} \mathrm{O}$ (279.34): C, 73.10; H, 6.13; N, 15.04. Found: C, 70.12; H, 6.15; N, 15.06.

1-Carboxamide-3-phenyl-5-(4-chloro-phenyl)-2-pyrazolines $\left(\mathrm{DS}_{21}\right)$ IR $(\mathrm{KBr})\left(\mathrm{v}_{\max } / \mathrm{cm}^{1}\right): 1587(\mathrm{C}=\mathrm{N}), 3035$ $\left(\mathrm{CH}_{2}\right), 1279(\mathrm{C}-\mathrm{N}), 1495\left(\mathrm{C}=\mathrm{C}\right.$ Ar.), $1691(\mathrm{C}=\mathrm{O}), 3491(\mathrm{~N}-\mathrm{H}), 693(\mathrm{C}-\mathrm{Cl}) ;{ }^{1} \mathrm{HNMR}\left(\mathrm{CDCl}_{3}\right) \delta \mathrm{H}: 3.14(\mathrm{dd}, 1 \mathrm{H}, J$ $\left.=5.30,17.6 \mathrm{~Hz}, \mathrm{H}_{\mathrm{A}}\right), 3.81\left(\mathrm{dd}, 1 \mathrm{H}, J=12.09,17.5 \mathrm{~Hz}, \mathrm{H}_{\mathrm{B}}\right), 5.50\left(\mathrm{dd}, 1 \mathrm{H}, J=5.26,12.04 \mathrm{~Hz}, \mathrm{H}_{\mathrm{X}}\right), 7.16-7.98(\mathrm{~m}, 9 \mathrm{H}$, $\mathrm{H}_{\text {arom }}$ ), 5.72 (br.s, $\left.2 \mathrm{H}, \mathrm{NH}_{2}\right)$; EIMS (m/z, \%): $299^{\circ}\left(\mathrm{M}^{+}, 16.3\right), 255^{\circ}(67), 144(100), 118(45), 104(68), 77(45), 55$ (16) ;Anal. Calcd for $\mathrm{C}_{16} \mathrm{H}_{14} \mathrm{~N}_{3} \mathrm{ClO}$ (299.76): C, 64.11; H, 4.71; N, 14.02. Found: C, 64.15; H, 4.75; N, 14.03.

I-Carboxamide-3-phenyl-5-(3-nitro-phenyl)-2-pyrazolines $\left(\mathrm{DS}_{22}\right) \mathrm{IR}(\mathrm{KBr})\left(\mathrm{v}_{\max } / \mathrm{cm}^{\prime}\right): 1592(\mathrm{C}=\mathrm{N}), 3021\left(\mathrm{CH}_{2}\right)$, $1282(\mathrm{C}-\mathrm{N}), 1489\left(\mathrm{C}=\mathrm{C}\right.$ Ar.), $1689(\mathrm{C}=\mathrm{O}), 3470(\mathrm{~N}-\mathrm{H})$; ' $\mathrm{HNMR}\left(\mathrm{CDCl}_{3}\right) \delta \mathrm{H}: 3.17\left(\mathrm{dd}, 1 \mathrm{H}, J=8,4 \mathrm{~Hz}, \mathrm{H}_{\mathrm{A}}\right)$, $3.79\left(\mathrm{dd}, 1 \mathrm{H}, J=12,12 \mathrm{~Hz}, \mathrm{H}_{\mathrm{B}}\right), 5.51\left(\mathrm{dd}, 1 \mathrm{H}, J=8,8 \mathrm{~Hz}, \mathrm{H}_{\mathrm{X}}\right), 7.21-7.90\left(\mathrm{~m}, 9 \mathrm{H}, \mathrm{H}_{\text {arom }}\right), 5.77\left(\mathrm{br} . \mathrm{s}, 2 \mathrm{H}, \mathrm{NH}_{2}\right)$; EIMS $(\mathrm{m} / \mathrm{z}$, 
$\%): 310\left(\mathrm{M}^{+}, 20.2\right), 266(72), 144(100), 118(46), 104(74), 77(46), 55$ (18) ;Anal. Calcd for $\mathrm{C}_{16} \mathrm{H}_{14} \mathrm{~N}_{4} \mathrm{O}_{3}(310.31)$ : C, 61.93; H, 4.55; N, 18.05. Found: C, 61.95; H, 4.53; N, 18.06.

\section{References}

1. S.S. Khan, and A. Hasan, Heterocyclic Commun. 12, 378 (2006)

2. R.V.K Kumar, V.Vijayabasker, S.Perumal, S..Selvaraj .and S. Natarajan, Acta Cryst, 60, 879 (2004).

3. Z.Y.Wang, H.J.Shi, and H.X.Shi, Hecheng Huaxue, 3, 226 (1995).

4. M.A.El-Hashash, E.M.A. Soiman, Z.M.Souka, and A.S.S. Salman, Rev. Roum. Chim, 40, 59 (1995).

5. M.A. Berghot,. and F.B. Moawad, Eur. J. Pharm. Sci., 20, 173 (2003).

6. J. Matysiak and A. Niewiadomy, Bioorg. \& Med. Chem., 11, 2285 (2003).

7. S. S. Parmer, B.R. Pandey, C. Dwivedi, and R.D.Harbison, J. Pharm. Sci., 63, 1152 (1947).

8. N. Soni, K. Pande, R. Kalsi, T.K. Gupta, S.S. Parmer, and J.P. Barthwal, Res. Commun. Chem. Pathol. Pharm. 56, 129 (1987).

9. G.Turan-Zitouni, P.Chevallet, F.S. Kilic, and K. Erol, K., Eur. J. Med. Chem. 35, 635 (2000).

10. T. Eicher, and E. Hauptmann, The Chemistry of Heterocycles, Thieme Verlog Stuttgart, New York (1995).

11. G.M. Badger, The Chemistry of Heterocycles, Academic Press, New York, London (1961).

12. R.M. Acheson, An Introduction to the Chemical Heterocyclic. Compounds, $3^{\text {rd }}$ Ed., John Wiley \& Sons, New York (1976).

13. S.G. Kücükgüzel, and S. Rollas, Farmaco, 47, 583 (2002).

14. E. Palaska, M. Aylemir, I.T. Uzbay, I.T. and D. Erol, Eur. J. Med. Chem., 36, 539 (2001).

15. M. Gabor, J. Sallai, T. Szelli, and G. Sipos, Acta. Microbiol. Acad. Sci. Hung., 14, 45 (1967).

16. D.A. Jacob, G. Lal, M.M. Sharma, and A. Singh, A., Curr Sci., 48, 961 (1979).

17. N.A.Abdou, K.M. Youssef, M.M. Kandeel, and L.M. Scliman, Bull. Fac. Pharm., 31, 361 (1993).

18. A. Syed, H.A. Eman, and M.P. Selim, Pak. J. Sci. Ind. Res., 39, 14 (1996).

19. A. Chowdhury, N. Mukherjee, and N.A. Chandhury, Experintia, 30, 1022 (1974).

20. J. Michael, A. Masood, and J. Alanzi., Heterocyclic Chem., 35, 65 (1998).

21. M. leven, B. Vanden, F. Mertens, A. Vlietinck, and E. Lammens, Planta Medica, 36, 311 (1979)

22. J.A. Waitz, and C.G.Drube, Antifungal Agents. Anu. Rep. Med. Chem., 7, 109 (1972)

23. W. Dawey and D.J.Tivey, J. Chem. Soc., 24, 1320 (1958).

24. H.M. Kohler H.and Chadwell (H. Gilman, and A.H., Blatt, Eds). Organic Syntheses, Wiley, New York, (1967).

25. H.S. Mehra, J. Indian Chem. Soc., 45, 178 (1968).

Received on February 18, 2997. 